\title{
The Effects of Task- Oriented Group Circuit Training on EEG for Chronic Stroke Patients
}

\author{
Bonggil Kim', Hyunghun Moon'2, Yonggon Seo ${ }^{3}$, Joonhee Kim4, \\ Jaeho Yu ${ }^{5}$, Hyeyoung Cho3 and Yunjin Park ${ }^{3 *}$ \\ 'Department of Physical Therapy, Gajwayonsei Orthopedics Clinic Seoul, Republic of Korea; \\ Realbong82@gmail.com \\ 2Department of Sports Medicine, Cha University, Pocheon, Republic of Korea; \\ moon7610@naver.com,moon7610@naver.com \\ ${ }^{3}$ Department of Sports Medicine, Korea University: Sejong City, Republic of Korea; Yongon79@naver.com, \\ nyxhy7756@naver.com, africca3535@gmail.com \\ 4Department of Sports Medicine, PPT Sports Academy, Seoul, Republic of Korea; Kjh417@korea.ac.kr \\ ${ }^{5}$ Department of Sports Medicine, Sun Moon University, Asan, Republic of Korea; naresa@sunmoon.ac.kr
}

\begin{abstract}
Background/Objectives: The purpose of this study was to invest the effect of task-oriented circuit training on EEG of $\alpha$-wave and $\beta$ wave for chronic stroke patients. Methods/Statistical Analysis: 30 chronic stroke patients were randomly divided into 2 Groups; Group Task-oriented Circuit training Group(GCG) and Individual task-oriented Circuit training Group(IGC). $\alpha$ and $\beta$ wave were evaluated before and after the training, which consists of warm up, exercise and cool down 3 times/week for 6 weeks. One-way ANOVA and paired t-testing were conducted to analysis and confirm the differences of the pre and post factors within each group. Findings: In the present result, the followings showed a statistically significant difference; $\alpha$ values for Fp1, Fp2, F3, F4, T3(p<.001)and $\beta$ values for Fp1, F3(p<.05)between the groups, the Fp1, Fp2, F3, F4 of the GCG(p<.001)andF3, F4 of the ICG(p<.001)at $\alpha$ values, Fp1, Fp2, F3, F4, T3, T4, P3,P4 of the GCC(p<.05) and Fp1, Fp2, F4, T3, T4, P3,P4of the IGC( $\mathrm{p}<.05)$ at $\beta$ values. Improvement/Application: These findings indicate that group taskoriented circuit training can be effective in $\alpha$-wave and $\beta$ wave for chronic stroke patients
\end{abstract}

Keywords: EEG, Stroke, Task-Oriented Circuit Training, $\alpha$-Wave, $\beta$ Wave

\section{Introduction}

Strokes are an ailment where there is abnormal cerebral blood flow due to blockage or rupture of the cerebral arteries, and this is a non-traumatic brain injury disease that accompanies neurological defects, which often occurs with various disabilities such as motor, sensory, perception, cognition, and language depending on the cause and location of the stroke. Because there can be severe limitations in daily activities and interacting with other people due to these disabilities, stoke patients suffer from emotional distress such as anxiety, depression and discouragement? In reported that $25-75 \%$ of stroke patients experienced depression accompanied by psychological distress and that self-efficiency, which is related to a loss of confidence, also decreased. These emotional impairments are known to contribute as main factors that block recovery from strokes which results in delayed recovery of sense of balance, motor functions and ability to walk while also exacerbating the chance for diseases to occurn. Therefore interest in the mental health state of stroke patients is very important, and there must be research conducted in diverse areas for stroke patients who continue to live on with physical and mental ailments . While rehabilitation for stroke patients has been conducted in various methods, preceding research has focused on a standardized physical function based on the assumption of the reversibility of the nerves and

${ }^{*}$ Author for correspondence 
also the practicing of repetitive and active movements of the unaffected limbs ${ }^{5}$. While exercise is an important intervention method for stroke patients, for patients with a decreased ability to exercise who experience decreased sensory feedback, because these exercise are conducted manually by a rehabilitation therapist, there can be difficulty in continuing treatment because motivation for the exercises can be difficult and interest in the exercises decreases . To supplement these issues, recent voluntary participation of rehabilitation exercises has been encouraged through motivating the patients using task-oriented training $[$. Task-oriented training is a form of exercise proposed by ${ }^{4}$ based on the motor learning theory from the 1980's which emphasized relearning motor functions through learning and training, and is a treatment method that provides patients with exercise assignments that are designed with the environment and goals that each individual patient needs. In 1 designed these task-oriented training exercises to help stroke patients with limited interpersonal relationships form a sense of community and empathy by conducting the exercises as group exercises, and this research study confirmed a statistically significant effect for the functional and emotional recovery of the patients.

Electroephalography (EEG), which is one of the clinical methods to diagnose strokes is a measurement index that reflects the physiological and psychological functions of the brain, and this index not only measures nerve activity but also enables continuous measurements over time. Also when compared to other image based clinical methods used to measure the functional activity of the brain, EEGs are less invasive, more economical, and also have the benefits that even examination data results taken over a short period of time can provide a significant amount of information to Therefore using changes in brain activation confirmed through EEGs, there is a need to objectively verify and interpret the emotional state of stroke patients. There are continuous research studies that report that exercise confirms a positive effect in the EEG monitoring results ${ }^{9-11 .}$ However, it is the reality that there is a lack of research on the effects of exercise on the brain activation of stroke patients in an unstable emotional state, and there is an even greater lack of research that compares the effects of individual and group exercises on the brain activation of stroke patients. Also because most research studies that examine task-oriented training are on the motor function improvements and treatment efficiency related to walking and ability to balance etc., there is a lack of research on what changes recovery through rehabilitation has on brain activation. Therefore this research study provided individual and group taskoriented circuit training exercises to stroke patients and examined what effects each of the exercises had on the a waves and $\beta$ waves of the EEG results.

\section{Materials}

\subsection{Study Participants}

This research study selected 30 chronic stroke patients whose strokes occurred more than 6 months ago from patients hospitalized at the $G$ rehabilitation hospital that were able to independently walk that did not have any difficulties communicating who also scored higher than 21 points on the MMSE-K(Mini-Mental State Examination) test, and randomly assigned these patients into one of the following two test groups: the Individual Task-oriented Circuit training Group (ICG) and Group Task-oriented Circuit training Group (GCG).

The test subjects that participated in this research study satisfied the following conditions, and after the subjects were adequately informed of the procedures and the purposes of this study, the test was conducted against patients who voluntarily filled out their written informed consent.

1) To eliminate the possibility of natural recovery, all patients were chronic patients whose strokes occurred more than 6 months ago

2) Patients who could independently walk 10 meters without any assistance

Table 1. Physical characteristics

\begin{tabular}{lcccccc}
\hline & Gender & Age(yrs.) & $\begin{array}{c}\text { Side of } \\
\text { hemiparesis }\end{array}$ & $\begin{array}{c}\text { Duration of } \\
\text { disease(month) }\end{array}$ & MMSE-K(score) & KGDS(score) \\
\hline ICG (n=15) & M: 8, F:7 & $50.93 \pm 9.26$ & Rt: 7, Lt: 8 & $20.67 \pm 8.43$ & $26.93 \pm 2.35$ & $18.67 \pm 3.99$ \\
GCG $(n=15)$ & M: 10, F:5 & $54.53 \pm 7.05$ & Rt: 7, Lt: 8 & $21.60 \pm 9.96$ & $25.60 \pm 3.18$ & $18.33 \pm 3.90$ \\
\hline
\end{tabular}

Group Task-oriented Circuit training Group (CTCG), Individual Task-oriented Circuit training Group (ICG).MMSE-K: Mini-mental state examination-korean, KGDS: Korea form of geriatric depression Scale 
3) Patients with depression symptoms above mild who scored higher than 14 points on the Korea form Geriatric Depression Scale (KGDS) and patients without visual and vestibular lesions that affected ability to balance

This study was approved by the University of Sunmoon Research Ethics Review Committee. (SYUIRB2010-007, 27 February 2015) as shown in Table 1.

\subsection{EEG Measurement}

Using QEEG-8 (LATTHA Inc., Korea), EEG measurements for the patients who had closed their eyes for 3 minutes in a noise proofed room after the patient was positioned to sit across from a familiar guardian to achieve psychological comfort. Electrodes were attached to the surface skin of the patients using an international 10/20 electrode system in the order of Lt Frontal pole1(Fp1), Rt Frontal pole2(Fp2), Lt Frontal 3(F3), Rt Frontal 4(F4), Lt Temporal3(T3), Rt Temporal4 (T4), Lt Parietal3 (P3), Rt Parietal4;(P4) for a total of 8 electrodes. After the reference electrode was attached to the right earlobe and the grounding electrode was attached to the forehead of the patient being measured, the measurement was taken using the monopolar technique. The frequency range was set as alpha, $\alpha$ wave $(8-13 \mathrm{~Hz})$, beta wave, $\beta(13-$ $30 \mathrm{~Hz}$ ), and after removing the delta, $\delta$ wave, which is highly influenced by movement of the eyes, pupils and facial muscles, the relative power of the relative $\alpha$ wave according to the remaining frequency range was analyzed.

\subsection{The Task-Oriented Circuit Training Program}

The task-oriented circuit training program was conducted with the objective of increasing the ability of the patient to walk according to strengthened muscles and improvements in the balance, speed and stamina required for walking, and by revising and supplementing the method proposed in the research of ${ }^{12}$ and ${ }^{17}$ to fit the needs of this research study, the method for his research study was designed to include 8 exercise sections. A training program that lasted 60 minutes that included 5 minutes of warm up, and 50 minutes of training (45 minutes of task-oriented training and a total of 5 minutes taken to move between each exercise sections), and 5 minutes of cool down exercises, which a rest time in between each training exercise section was not provided. If the test subjects complained of fatigue during the training they were recommended to take a rest period, and after taking a break they continued to participate in the training. The speed and difficulty for each section was increased based on the agreement of the participant, and to provide the detailed objectives for each assigned exercise and also for the safety of the participants, a therapist was stationed at each exercise section to give orders and monitor the patients. To enable the group task-oriented circuit training to encourage the maximum results of the exercise through the increase in motivation and competitive spirit for each individual participant, each patient was assigned a 'partner' to form groups of 2 or 3 patients together ${ }^{13}$. The task-oriented circuit training program is shown in Table 2.The individual task-oriented circuit training program was strictly conducted 1:1 between a patient and a therapist using the same exercises and the same environments as those used for the GCG group.

\subsection{Data Analysis}

All data collected from this research study was analyzed to calculate the mean (M) and standard deviation (SD) using the SPSS/PC 18.0 statistics program in a Windows environment. One-way ANOVA was conducted to analysis the differences in the pre and post factors according to exercise method and measurement duration, and paired t-testing was conducted to confirm the pre and post factors within each group.

\section{Results}

\subsection{Change to Prefrontal Area after the 6 Week Program}

As shown in Table 3, while the results of the paired t-test confirmed that Fp1 and Fp2 for the a wave showed a statistically significant difference $(\mathrm{p}<.001)$ for GCG, there were no statistically significant differences confirmed for ICG. Fp1 and Fp2 for the $\beta$ wave showed a statistically significant difference for GCG and ICG $(\mathrm{p}<.05)$. The results of the One-way ANOVA confirmed that Fp1 and $\mathrm{Fp} 2$ for the a wave showed a statistically significant difference $(\mathrm{p}<.001)$ for all groups, while for the $\beta$ wave only Fp1 showed a statistically significant difference. $(\mathrm{p}<.05)$. 
Table 2. Task- oriented circuit training program

\begin{tabular}{|c|c|c|c|c|c|c|}
\hline Duration & \multicolumn{2}{|c|}{$\begin{array}{l}\text { Type } \\
\text { / Exercise Section }\end{array}$} & Training program & Training objective & Time $(\min )$ & RPE \\
\hline \multirow[t]{10}{*}{$\begin{array}{l}1 \sim 6 \\
\text { weeks }\end{array}$} & \multicolumn{2}{|c|}{ Warm up exercises } & $\begin{array}{l}\text { ankle joint dorsiflexion and plantarflexion } \\
\text { exercise/shoulder flexion and elevation } \\
\text { exercise }\end{array}$ & $\begin{array}{l}\text { Joint exercises and } \\
\text { Improvement in } \\
\text { muscular strength } \\
\end{array}$ & 5 & $8 \sim 9$ \\
\hline & \multirow[t]{8}{*}{$\begin{array}{l}\text { Main } \\
\text { exercises }\end{array}$} & Lift feet & $\begin{array}{l}\text { use hand as aid on the test side / without } \\
\text { hand as aid/put feet up on floor board at } \\
7 \mathrm{~cm}, 15 \mathrm{~cm} \text {, and } 20 \mathrm{~cm} \text { distances/step up and } \\
\text { down from floor board/increase number of } \\
\text { times within a set period of time }\end{array}$ & active balancing & 5 & \multirow[t]{9}{*}{$\begin{array}{c}10 \\
\sim 15\end{array}$} \\
\hline & & $\begin{array}{l}\text { Kick a ball to- } \\
\text { wards the wall }\end{array}$ & $\begin{array}{l}\text { use hand as aid on the test side / without } \\
\text { hand as aid/trap ball with foot on test side at } \\
1 \mathrm{~m}, 1.5 \mathrm{~m} \text { and } 2 \mathrm{~m} \text { distances }\end{array}$ & active balancing & 5 & \\
\hline & & $\begin{array}{l}\text { Stand and walk } \\
\text { after being in the } \\
\text { sitting position }\end{array}$ & $\begin{array}{l}\text { use } 4 \text { chairs } 40 \mathrm{~cm} \text { high chair with arm rests } \\
\text { / without arm rests/form a square with } 5 \mathrm{~m} \\
\text { between each chair, increase the number of } \\
\text { round trip exercises within a given time }\end{array}$ & $\begin{array}{l}\text { active balancing, } \\
\text { walking, } \\
\text { increase muscular } \\
\text { strength in lower } \\
\text { limbs }\end{array}$ & 5 & \\
\hline & & $\begin{array}{l}\text { Walk an obstacle } \\
\text { course }\end{array}$ & $\begin{array}{l}\text { walk while avoiding obstacles/ setup cone } \\
\text { shaped obstacles at } 1 \mathrm{~m}, 75 \mathrm{~cm} \text { and } 50 \mathrm{~cm} \\
\text { distances/walk up and over obstacles } / \text { use } \\
\text { Rolls of dimensions }(45 \mathrm{~cm} \times 10 \mathrm{~cm} \times 8 \mathrm{~cm}) \text {, } \\
(60 \mathrm{~cm} \times 15 \mathrm{~cm} \times 12 \mathrm{~cm}) / \text { setup at } 1 \mathrm{~m}, 75 \mathrm{~cm} \text {, } \\
50 \mathrm{~cm} \text { distances }\end{array}$ & Walking balance & 5 & \\
\hline & & $\begin{array}{l}\text { Walk at max } \\
\text { speed }\end{array}$ & $\begin{array}{l}\text { improve the maximum distance walked in a } \\
\text { set period of time }\end{array}$ & Walking stamina & 5 & \\
\hline & & $\begin{array}{l}\text { Walk on a tread- } \\
\text { mill }\end{array}$ & $\begin{array}{l}\text { continuously improve speed from } 0.8 \mathrm{~km} / \mathrm{h} \\
\text { to } 4 \mathrm{~km} / \mathrm{h}\end{array}$ & Walking stamina & 10 & \\
\hline & & $\begin{array}{l}\text { Sit on a Swiss } \\
\text { ball }\end{array}$ & $\begin{array}{l}\text { use hand as aid on the test side / without } \\
\text { hand as aid/sit on ball/rotate pelvis while on } \\
\text { top of ball/twist body while on top of ball to } \\
\text { look in the rear direction/run while on top } \\
\text { of ball using two lower limbs }\end{array}$ & $\begin{array}{l}\text { active balancing, } \\
\text { increase muscular } \\
\text { strength in lower } \\
\text { limbs }\end{array}$ & 5 & \\
\hline & & Video games & play sports game in 2 person teams & $\begin{array}{l}\text { Interactionand } \\
\text { active balancing }\end{array}$ & 5 & \\
\hline & \multicolumn{2}{|c|}{ Cool down exercises } & breathing exercises while sitting, rest & Relax body & 5 & \\
\hline
\end{tabular}

\subsection{Change to Frontal Area after the 6 Week Program}

Asshown in Table3, the results of the paired t-testconfirmed that F3 and F4 for the a wave showed a statistically significant difference for GCG and ICG( $\mathrm{p}<.001)$. F3 for the $\beta$ wave showed a statistically significant difference for GCG $(\mathrm{p}<.001)$ while F4 showed a statistically significant difference for both GCG and ICG(p<.05).The results of the One-way ANOVA confirmed that F3 and F4 for the a wave showed a statistically significant difference $(\mathrm{p}<.001)$ for all groups, while for the $\beta$ wave only F3 showed a statistically significant difference $(\mathrm{p}<.05)$.

\subsection{Change to Temporal Area after the 6 Week Program}

As shown in Table 3, the results of the paired t-test confirmed that there were no statistically significant differences for the $\alpha$ wave. T3 and T4 for the $\beta$ wave showed a statistically significant difference for both GCG and ICG $(p<.05)$. The results of the One-way 
ANOVA confirmed that only T3 for the a wave showed a statistically significant difference $(\mathrm{p}<.001)$.

\subsection{Change to Parietal Area after the 6 Week Program}

As shown in Table 3, the results of the paired t-test confirmed that there were no statistically significant differences for the $\alpha$ wave. P3 and P4 for the $\beta$ wave showed a statistically significant difference for both GCG and ICG $(\mathrm{p}<.05)$. The results of the One-way ANOVA confirmed that there were no statistically significant differences for both the $\alpha$ wave and also the $\beta$ wave for all groups.

\section{Discussion}

Task-oriented training has the objective of improving the ability to adopt environmental change through exercises execution. Therefore when the assigned exercises are being performed, these exercises must be performed step by step through analyzing the objectives and environment of the exercises assigned to the patient. . Also through repeated execution of assigned exercises, the patient is made to re-acquire the techniques related to motor functions. But no matter how well designed an exercise program is provided, if there is inadequate participation by the patient, it is difficult to achieve effective results. Therefore it is important to continuously provide motivation so that patients can continuously participate in the exercise programs. Examples for motivation include having the guardian of the patient actively recommend participation and also to provide an environment where the patients can exercise together with other patients in the same situation. It has been reported that group exercises increase the intimacy and closeness in interpersonal relationships and improve social integration functions, which significantly contribute to improvements in physical execution ability and also emotional stability ${ }^{14}$. Therefore as a method to overcome any difficulties associated with performing these exercises, the positive effects of group exercises have recently been reported. $\mathrm{In}^{13}$ grouped 2 stroke patients into 1 group, and the results of providing task-oriented circuit training that had the objective of improving walking ability, while it was shown that not only gait ability, but in addition to a decrease in depression and anxiety, positive effects in terms of emotion control were also confirmed, for groups where 1:1 individual exercise training was

Table 3. Change to $\alpha$ and $\beta$ wave after the 6weeks

\begin{tabular}{|c|c|c|c|c|c|c|}
\hline & & \multicolumn{2}{|c|}{$\operatorname{GCG}(n=15)$} & \multicolumn{2}{|c|}{ ICG $(n=15)$} & \multirow[t]{2}{*}{$\mathrm{F}$} \\
\hline & & pre & post & pre & post & \\
\hline \multirow[t]{2}{*}{ Fp1 } & alpha & $.324 \pm .244$ & $.558 \pm .224 \# \# \#$ & $.319 \pm .166$ & $.336 \pm .163$ & $67.441^{\star * *}$ \\
\hline & beta & $.129 \pm .048$ & $.231 \pm .100 \# \#$ & $.205 \pm .069$ & $.290 \pm .103 \#$ & $.030^{*}$ \\
\hline \multirow[t]{2}{*}{ Fp2 } & alpha & $.343 \pm .251$ & $.582 \pm .245 \# \# \#$ & $.331 \pm .163$ & $.339 \pm .162$ & $58.978^{* * *}$ \\
\hline & beta & $.120 \pm .049$ & $.220 \pm .105 \# \#$ & $.206 \pm .073$ & $.300 \pm .114 \#$ & .907 \\
\hline \multirow[t]{2}{*}{ F3 } & alpha & $.382 \pm .233$ & $.600 \pm .215 \# \# \#$ & $.374 \pm .116$ & $.428 \pm .112 \# \# \#$ & $94.327^{\star * *}$ \\
\hline & beta & $.137 \pm .063$ & $.307 \pm .100 \# \# \#$ & $.209 \pm .071$ & $.274 \pm .116$ & $.015^{\star}$ \\
\hline \multirow[t]{2}{*}{$\mathrm{F} 4$} & alpha & $.387 \pm .240$ & $.609 \pm .207 \# \# \#$ & $.381 \pm .111$ & $.408 \pm .112 \# \# \#$ & $77.274^{* * *}$ \\
\hline & beta & $.129 \pm .053$ & $.262 \pm .108 \# \# \#$ & $.204 \pm .076$ & $.283 \pm .106 \#$ & .181 \\
\hline \multirow[t]{2}{*}{ T3 } & alpha & $.273 \pm .131$ & $.350 \pm .205$ & $.243 \pm .085$ & $.268 \pm .145$ & $.335^{\star * *}$ \\
\hline & beta & $.168 \pm .061$ & $.294 \pm .107 \# \# \#$ & $.225 \pm .077$ & $.314 \pm .118 \#$ & .406 \\
\hline \multirow[t]{2}{*}{$\mathrm{T} 4$} & alpha & $.255 \pm .133$ & $.315 \pm .239$ & $.213 \pm .109$ & $.196 \pm .139$ & .458 \\
\hline & beta & $.162 \pm .072$ & $.315 \pm .118 \# \# \#$ & $.230 \pm .092$ & $.356 \pm .083 \# \# \#$ & .575 \\
\hline \multirow[t]{2}{*}{ P3 } & alpha & $.342 \pm .189$ & $.414 \pm .236$ & $.263 \pm .077$ & $.327 \pm .145$ & .891 \\
\hline & beta & $.142 \pm .056$ & $.261 \pm .115 \# \#$ & $.208 \pm .069$ & $.295 \pm .100 \#$ & .424 \\
\hline \multirow[t]{2}{*}{$\mathrm{P} 4$} & alpha & $.306 \pm .171$ & $.401 \pm .251$ & $.252 \pm .119$ & $.277 \pm .137$ & .289 \\
\hline & beta & $.164 \pm .062$ & $.266 \pm .124 \#$ & $.226 \pm .084$ & $.291 \pm .098 \#$ & .422 \\
\hline
\end{tabular}

Values are means \pm standard deviation GTG: Group task-oriented circuit Training Group, ITG: Individual task-oriented circuit Training Group \#: Significantly difference within in paired t-test, \#: $\mathrm{p}<.05$, \#\#p<.01, \#\#\#.001*: Significantly difference by time one way ANOVA analysis of variance, ${ }^{*}$ : $\mathrm{p}<.05,{ }^{* *} \mathrm{p}<.01,{ }^{* * *}<.001$ 
performed, positive effects related to depression and anxiety decreasing were not possible to be confirmed. As can be seen from such preceding research, it could be confirmed that while task-oriented circuit training was provided, the importance of performing these exercises in groups was possible to be confirmed in terms of achieving improvement in the psychological health of the stroke patients. Therefore by providing task-oriented circuit training to chronic stroke patients by dividing them into individual exercises groups and group exercises groups, the effects of how the exercises were performed on brain activation were comparatively analyzed.

The a values for Fp1, Fp2, F3, F4, T3 between the groups showed a statistically significant difference. Because the forebrain is part of the brain cortex area with a close connection with physical activity, this area of the brain responds sensitively to electrical rhythm ${ }^{15}$. Therefore the fact that the task-oriented circuit training program provided in this research study showed a statistically significant improvement in the forebrain area means that compared to other regions of the brain, the forebrain area was activated more to execute motor functions. Also in comparison to Fp1, Fp2, F3 and F4 for GCG which showed a statistically significant improvement within each group, showed a statistically significant improvement was only shown in F3 and F4 for ICG. As a stable wave that is mainly generated during a stable emotional state ${ }^{16}$, the a wave usually occurs when the patient is relaxed, when they close their eyes, and when they are in a comfortable emotional state. Therefore these results can be interpreted to mean that regular exercise can provide emotional stability to chronic stroke patients. The results of the research study conducted by that compared the changes in the brain activation in elderly people for before and after walking reported a statistically significant improvement of $\alpha$ wave in the frontal area immediately after exercise and that exercise was effective for increasing emotional stability.

The results of this research study that confirms that the a wave in the forebrain area improved statistically significantly more for GCG than ICG is considered to be due to an increase emotional stability that occurred due to an increase in the intimacy and familiarity in interpersonal relationship and social integration functions that were a result of exercising together with other patients in the same situation ${ }^{\text {a }}$. This is a similar result to the research study off that reported that $\alpha$ waves were shown to be statistically significant for before and after aerobic exercises were performed. In 18 examined the brain activation in Alzheimer's disease patients for 4 years at 6 month intervals, and confirmed that there was a statistically significant decrease in the brain activation for frequencies greater than $8 \mathrm{~Hz}$. Decreases in $\beta$ waves have been shown to be related to cognitive function disability' The forebrain is especially know to be an area of the brain that shows high levels of activation when brain functions are being performed, and that the cerebral hemisphere has an influence on the generation of voluntary and selfmotivation? The results of this research study confirmed Fp1 and F3 for the $\beta$ wave showed a statistically significant difference for all groups. Also with the exception of factor T3 for GCG, and for Fp1, Fp2, F4, T3, T4, P3, P4 for, ICG statistically significant differences for all groups were confirmed. This means that the $\beta$ wave is more active after exercises are performed. In ${ }^{2}$ reported high brain activation in the multiplex space range in the $\beta$ wave for healthy test participants who performed aerobic exercises, and 19 reported statistically significant improvements in the $\beta$ waves of the left and right frontal lobes for healthy male test participants who performed cycling exercises. While the test subjects in these research studies were not elderly people with dementia, these results can be interpreted to mean that regular exercise in general affects the brain activation of $\beta$ waves. The reason that the $\beta$ waves generated when engaging in cognitive functions showed statistically significant differences in the forebrain area is probably due to the high correlation between exercise and cognitive function?

\section{Conclusion}

When engaging in active voluntary practice to learn functions, and by successfully achieving motion in order to achieve the objectives of task-oriented circuit training, a sense of satisfaction and achievement can be derived. Group exercises promote forming a relationship of empathy and intimacy and familiarity in order to achieve a common goal with partners, and by positively contributing to the physical state and emotional stability of patients, group exercises have been concluded to be effective intervention methods that can improve the quality of life of patients 


\section{References}

1. Lee S-R. A Design of Clinical Information Model to Improve Self-care Activities in Participants with Stroke. Indian Journal of Science and Technology. 2015; 8(18):1-6.

2. Pohjasvaara T, Vataja R, LeppavuoriA, Kaste M, Erkinjuntti T. Depression is an independent predictor of poor longterm functional outcome post-stroke. European Journal Neurology. 2001; 8(4):315-9.

3. Hadidi N. Treat-Jacobson D J, Lindquist R. Post-stroke depression and functional outcome: a critical review of literature. Heart and Lung. 2009; 38(2):151-62.

4. Carr JH, Shepherd RB. Stroke rehabilitation: Guideline for exercise and training to optimize motor skill. London, Butterworth Heinemann medical, Oxford. 2003.

5. Shumway-Cook A, Woollacott M. Motor control: translating research into clinical practice (3rd ed.). Philadelphia: Lippincott Williams \& Wilkins. Wevers. 2009; 1-113.

6. Dean CM, Richards CL, Malouin F. Task-Related Circuit Training Improves Performance of Locomotor Tasks in Chronic Stroke: A Randomized, Controlled Pilot Trial. Archives Physical Medicine Rehabilitation. 2000; 81(4):40917.

7. Yang YR, Wang RY, Lin KH, Chu MY, Chan RC. Task-oriented progressive resistance strength training improves muscle strength and functional performance is individuals with stroke. Clinical Rehabilitation. 2006; 20(10):860-70.

8. English CK, Hillier SL, Stiller KR. Warden-Flood. Circuit Class Therapy Versus Individual Physiotherapy Sessions During Inpatient Stroke Rehabilitation: A Controlled Trial. Archives Physical Medicine Rehabilitation. 2007; 88(8):955-63.

9. Sburlea AI, Montesano L, de la Cuerda RC, Diego IMA, Miangolarra-Page JC, Minguez J. Detecting intention to walk in stroke patients from pre-movement EEG correlates. Journal of Neuro Engineering and Rehabilitation. 2015; 12:113-25.

10. Choi W, Lee S, Park J. EEG-biofeedback Intervention Improves balance in Stroke Survivor. Indian Journal of Science and Technology. 2015; 8(18):1-6.

11. Wijdicks E, Sheth KN, Carter B, Greer DM, Kasner SE, Kimberly T, Schwab S, Smith EE, Tamargo RJ, Wintermark M. and on behalf of the American Heart Association Stroke Council. Recommendations for the management of cerebral and cerebellar infarction with swelling:a statement for healthcare professionals from the American Heart
Association/American Stroke Association. Stroke. 2014; 45(4):1222-38.

12. Salbach NM, Nancy E, Robichaud-Ekstrand S, Hanley JA, Richards CL, Wood-Dauphinee S. The Effect of a Task-Oriented Walking Intervention on Improving Balance Self-Efficacy Poststroke: A Randomized, Controlled Trial. Journal American Geriatrics Society. 2005; 53(4):576-82.

13. van de Port I, Wevers L, Roelse H, van Kats L, Lindeman E, Kwakkel G. Cost-effectiveness of a structured progressive task-oriented circuit class training programme to enhance walking competency after stroke: The protocol of the FITStroke trial. BidMed Central Neurology. 2009; 9:43-51.

14. Reuter I, Engelhardt M. Exercise training and Parkinson's disease: placebo or essential treatment? Physician and Sports Medicine. 2002; 30(3):43-50.

15. Gontkovsky ST, McDonald NB, Clark PG, Ruwe WD. Current directions in computer-assisted cognitive rehabilitation. Neurorehabilitation. 2002; 17(3):195-9.

16. Vogt T, Schneider S, Brummer V, Studes HK. Frontal EEG asymmetry: The effects of sustained walking in the eldery. Neuroscience Letter. 2010; 485(2):134-7.

17. Boutcher SH, Landers DM. The effects of vigorous exercise on anxiety, heart rate, and alpha activity of runners and nonrunners. Psychophysiology. 1993; 25(6):696-702.

18. Michel CM, Grave de Peralta R, Lantz G, Gonzalez Andino S, Spinelli L, Blanke O, Landis T, Seeck M. Spatiotemporal. EEG analysis and distributed source estimation in presurgical epilepsy evaluation. Journal Clinical Neurophysiology. 1999; 16(3):239-66.

19. Michel CM, Grave de Peralta R, Lantz G, Gonzalez Andino S, Spinelli L, Blanke O, Landis T, Seeck M. Beta and alpha electroencephalographic activity changes after acute exercise. Arquivos de Neuro-Psiquiatria. 2007; 65(3a):637-41.

20. Rice DM, Buchsbaum MS, Starr A, Auslander L, Hagman J. Abnormal EEG slow activity in left temporal areas in senile dementia of the Alzheimer type. Journal of Gerontology. 1990; 45(4):145-51.

21. Schneider S, Brümmer V, Abel T, Askew CD, Strüde HK. Changes in brain cortical activity measured by EEG are related to individual exercise preferences. Physiology and Behavior. 2009; 98(4):447-52.

22. Miller R. Theory of the normal waking EEG: from single neurones to wave forms in the alpha, beta and gamma frequency ranges. International Journal of Psychophysiology. 2007; 64(1):18-23. 